\title{
Statins for Renal Patients: A Fiddler on the Roof?
}

\author{
Anabela Malho Guedes and Pedro Leão Neves \\ Serviço de Nefrologia, Hospital de Faro, 8000 Faro, Portugal \\ Correspondence should be addressed to Anabela Malho Guedes, anabelamalho@hotmail.com
}

Received 17 July 2012; Revised 22 September 2012; Accepted 24 September 2012

Academic Editor: Alessandro Amore

Copyright ( 2012 A. M. Guedes and P. L. Neves. This is an open access article distributed under the Creative Commons Attribution License, which permits unrestricted use, distribution, and reproduction in any medium, provided the original work is properly cited.

\begin{abstract}
Atherosclerotic cardiovascular disease is the main cause of morbidity and mortality in chronic kidney disease patients. There is a raft of evidence showing that in the general population dyslipidaemia is associated with an increased risk of cardiovascular events, as well as with a greater prevalence of chronic kidney disease. Consequently, the use of statins in the general population with dyslipidaemia is not controversial. Nevertheless, the benefits of statins in patients with chronic kidney disease are more elusive. The authors review the possible effects of statins on the progression of renal disease and cardiovascular events in chronic kidney disease patients.
\end{abstract}

\section{Introduction}

Atherosclerotic cardiovascular disease is the main cause of morbidity and mortality in chronic kidney disease patients $[1,2]$, with many factors such as high blood pressure, dyslipidaemia, increased oxidative stress and inflammation, diabetes, and mineral metabolism imbalances contributing to this [3]. As the pathophysiology of atherosclerosis and glomerulosclerosis is similar [3], it is not surprising to find they have the same risk factors [3]. There is a raft of evidence showing that in the general population dyslipidaemia is associated with increased risk of cardiovascular events [4], as well as with a greater prevalence of chronic kidney disease $[5,6]$. Consequently, the use of statins in the general population with dyslipidaemia is not controversial. Nevertheless, the benefits of statins in patients with chronic kidney disease are more elusive. The aim of this work is to review the possible effects of statins on the progression of renal disease and cardiovascular events in chronic kidney disease patients.

\section{Dyslipidaemia and Chronic Kidney Disease}

2.1. Effect on Renal Function. It is still uncertain whether dyslipidaemia itself causes kidney disease progression or whether kidney impairment and proteinuria are responsible for both renal disease progression and dyslipidaemia [7]. Evidence suggests that in the early stages of renal impairment, dyslipidaemia increases the likelihood of CKD and may also accelerate its progression by promoting intrarenal atherogenesis and cellular impairment in the microvasculature [8]. The role of dyslipidaemia in promoting kidney damage has been shown in experimental models. Rats fed a diet rich in cholesterol and fat exhibited increased numbers of glomeruli with sclerotic foci and of glomeruli with lipid deposits.

The severity of the hypercholesterolemia correlates with proteinuria. In rats with kidney disease caused by unilateral nephrectomy, such diet augmented the glomerular lesions in the remaining kidney [9]. Renal biopsies from patients with glomerular disease indicate that lipoproteins accumulate in both glomerular and mesangial cells and within the mesangial matrix, and oxidised lipids are frequently found in biopsy specimens from patients with renal disease $[8,10]$. The presence of lipids in renal cells exerts a nephrotoxic effect and accelerates glomerulosclerosis, by upregulating intracellular signalling pathways involved in inflammatory and fibrogenic responses, both of which are implicated in progressive renal injury $[11,12]$.

Samuelsson et al., in a small study with 73 adult nondiabetic patients with primary chronic renal disease, showed that lipoprotein abnormalities can contribute to the progression of kidney failure in CKD patients and demonstrated 
an association between progression of renal disease and hyperlipidaemia [11]. The Physicians' Health Study followed 4483 healthy men, at the outset, for a mean of 14.2 years. After adjustment for potential confounding factors (cardiovascular risk factors and development of hypertension and cardiovascular disease), men in the highest quartile of total cholesterol/high-density lipoprotein cholesterol ratio had a $92 \%$ higher risk of developing CKD than those in the lowest quartile [13].

The Helsinki Heart Study documented an association between dyslipidaemia and progressive kidney disease in 2702 middle-aged dyslipidaemic men. Renal function deteriorated by a mean of $3 \%$ over 5 years, and although hypertension accelerated this change, the decline was faster by $20 \%$ in men with an LDL: HDL ratio $>4.4$ than in men with a ratio $<3.2$. After multiple regression analyses, the only measures having a significant effect on the observed phenomenon were an increased LDL: HDL ratio (negative outcome) and an increased HDL-C level (protective outcome) $[5,8]$.

2.2. Effect on Cardiovascular Disease. The lipid profile is influenced by the severity of renal dysfunction and the presence of proteinuria. Patients with CKD have, in general, lower levels of HDL, LDL, and total cholesterol and higher levels of triglycerides. There is a clustering of low HDL and elevated Lp(a) and TG-rich ApoB containing VLDL and IDL [14]. Patients with nephrotic syndrome have increased levels of all Apo-B containing lipoproteins (VLDL, IDL, and LDL) and decreased levels of HDL [14]. Although dyslipidaemia has an important role in CKD-associated atherosclerosis, the relationship between cardiovascular (CV) events and cholesterol levels in this particular population is not straightforward. Almost 150 years ago, Virchow described atherosclerosis as an inflammatory disease.

In the last decades the medical literature confirmed that oxidative stress and inflammation are major players in the pathogenesis of atherosclerosis [15], and more recently, it has been well described that chronic kidney disease is characterised by increased oxidative stress and inflammation $[16,17]$. Despite normal or low cholesterol levels, in renal patients there is a greater proportion of the more atherogenic LDL oxidised form [14]. This fact can in part explain why in CKD patients there is a strong relationship between inflammatory markers and $\mathrm{CV}$ hard endpoints and patients with low cholesterol levels may have poor outcomes. This inverse relationship between cholesterol levels and cardiovascular events, in marked contrast to the general population, is called reverse epidemiology. Renal patients with low cholesterol levels tend to be malnourished and more "inflamed." This association of malnutrition, inflammation and atherosclerosis was well described by Stenvinkel et al. and called the MIA syndrome [18].

\section{Does the Use of Statins Lower the Progression of Renal Disease?}

If dyslipidaemia promotes renal injury, then reducing dyslipidaemia should slow or prevent the progression of CKD.
Experimental models show that statins decrease the severity of glomerular damage and preserve renal function. For example, New Zealand rabbits fed a diet rich in cholesterol became hypercholesterolaemic, with evidence of endothelial dysfunction in renal segmental arteries as well as glomerular hypertrophy and diffuse glomerulosclerosis. In this model, atorvastatin attenuated the increase in plasma cholesterol and prevented renal artery endothelial dysfunction, glomerular hypertrophy, and most of the glomerulosclerosis [19]. Data on the efficacy of statin therapy in patients with renal dysfunction is limited, as these patients were excluded from early statin trials [9]. The majority of these data come from post hoc analyses or from patients randomised for cardiovascular primary endpoint trials [20] (Table 1).

3.1. Statins and Proteinuria. The presence of proteinuria is an indicator of kidney disease with an increased probability of progressive kidney failure and is associated with faster loss of GFR compared with little or no proteinuria [20]. In a meta-analysis by Sandhu et al., the effects of statins on proteinuria and albuminuria were evaluated in 9 studies (350 participants) and 7 studies (904 participants), respectively. When proteinuria and albuminuria were considered separately, statin therapy did not significantly influence the rate of change in urinary protein or albumin excretion. However, when considered together, statins significantly reduced urinary protein and albumin excretion compared with controls (standardised mean difference between treatments, -0.58 units of SD) [21].

A meta-analysis by Douglas et al. evaluated 15 studies involving a total of 1,384 patients and examined the proportional reduction in proteinuria with the use of statins. It was shown that statins reduced albuminuria and proteinuria in 13 of the 15 studies. The reduction of excretion was greater among studies with greater baseline albuminuria or proteinuria. More specifically, 440 patients with albuminuria $\geq 30 \mathrm{mg} /$ day showed a $48 \%$ reduction of albuminuria relative to placebo [22].

Another meta-analysis of six randomised placebo control trials including 311 patients showed that compared to placebo, statins reduced proteinuria significantly $(-0.73 \mathrm{~g} / 24 \mathrm{~h})$ [23]. A differential effect on proteinuria has also been suggested, with different statins. PLANET I (Prospective Evaluation of Proteinuria and Renal Function in Diabetic Patients with Progressive Renal Disease) and PLANET II (Evaluation of Proteinuria and Renal Function in Nondiabetic Patients with Progressive Renal Disease), two related randomised, double-blind, parallel-group, multinational, multicentre, phase IIb trials, evaluated the effects of atorvastatin and rosuvastatin on urinary protein excretion and kidney function from baseline to week 52 in hypercholesterolaemic diabetic and nondiabetic patients, respectively.

In PLANET I, atorvastatin $(80 \mathrm{mg})$ significantly reduced proteinuria by about $15 \%$, whereas rosuvastatin (10 or $40 \mathrm{mg}$ ) had no significant effect on proteinuria. In PLANET II, atorvastatin $(80 \mathrm{mg})$ reduced proteinuria by $23.8 \%(P=$ 0.0056) [20]. Discrepant findings have been reported in some studies, as short-term therapy with statins, particularly at 


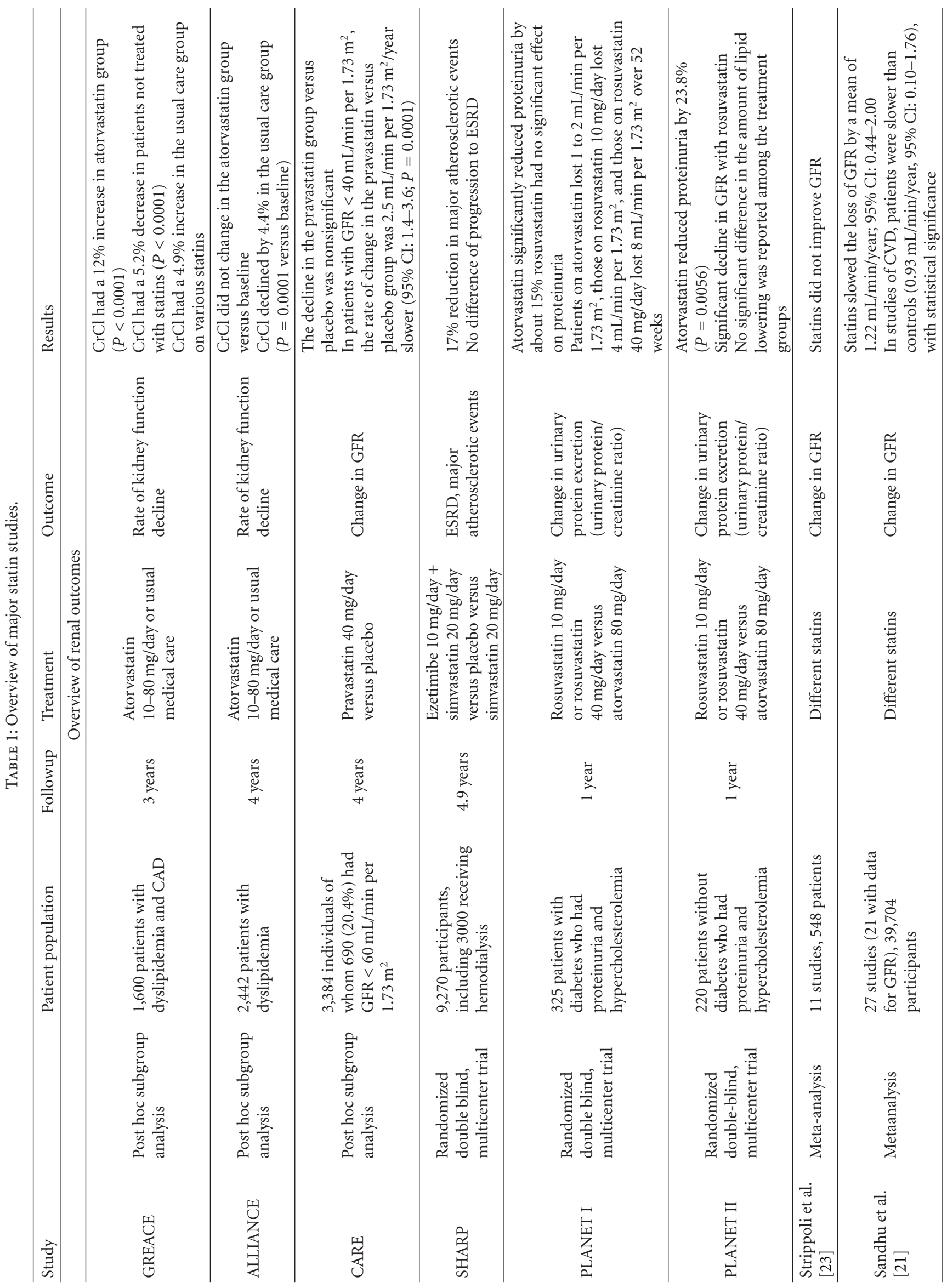




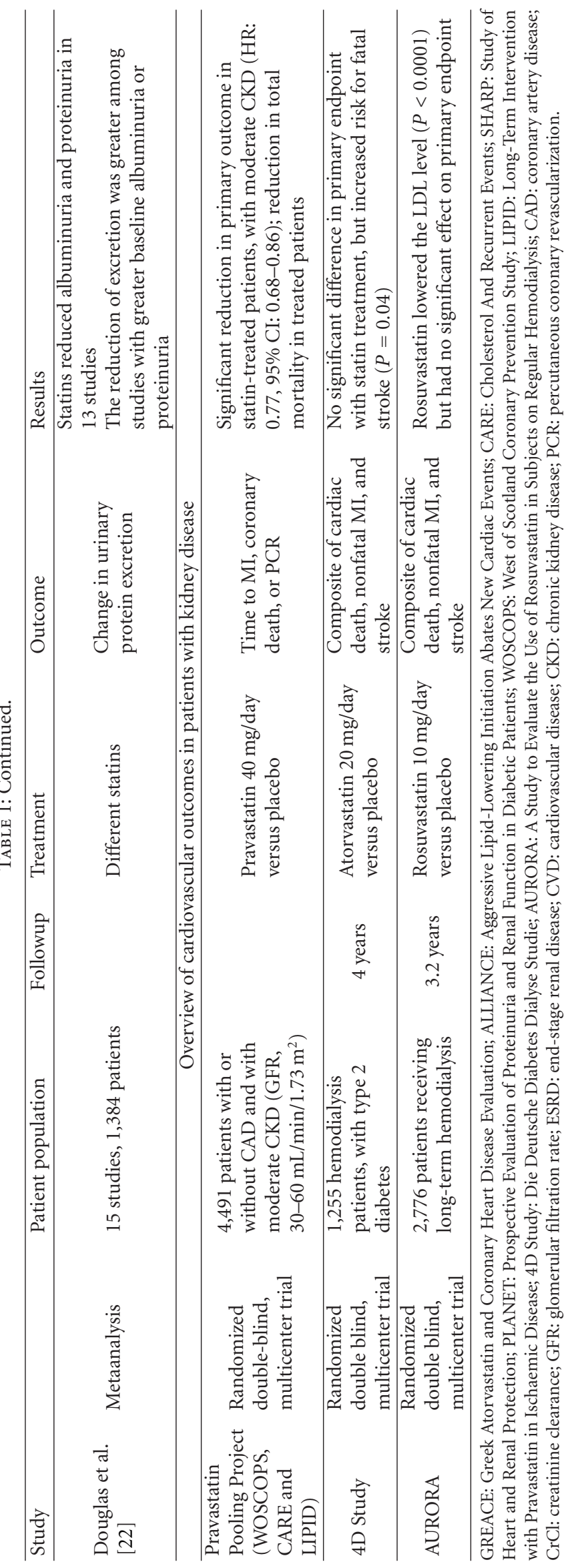


high doses, can induce proteinuria. Urinary protein electrophoresis indicated that most of the protein excreted had a lower molecular weight than albumin, suggesting that this may be due to reduced receptor-mediated endocytosis in proximal tubular cells $[9,20,24]$. This may help explain why statins can transiently increase protein excretion and simultaneously protect against renal damage.

The National Lipid Association Statin Safety Assessment Task Force reported that "proteinuria is at least possible with all statins at some concentration, but is more likely to be seen with statins that are potent inhibitors of HMG-CoA reductase." The report concludes that statin-induced proteinuria is not associated with either renal impairment or renal failure $[9,25]$. Accordingly, proteinuria is not a reliable surrogate endpoint for important renal outcomes, when we are assessing the effects of statins in CKD patients.

3.2. Statins and CKD Progression. Two trials-the Greek Atorvastatin and Coronary Heart Disease Evaluation (GREACE) study and the Aggressive Lipid-Lowering Initiation Abates New Cardiac Events (ALLIANCE) study_-evaluated atorvastatin therapy versus usual care in patients with coronary artery disease (CAD). In both studies, creatinine clearance declined by an average of $4.4 \%$ during 4 years in patients assigned to usual care. In contrast, patients assigned to atorvastatin therapy had an $11.6 \%$ increase in creatinine clearance in the GREACE study. In the atorvastatin group in the ALLIANCE study, although creatinine clearance did not improve, no decline was seen. The difference between treatments was highly significant in both studies $(P<0.0001)$ $[26,27]$.

A Post Hoc analysis of the Cholesterol and Recurrent Events (CARE) trial, a secondary prevention trial of pravastatin versus placebo, showed a significant difference in the rate of decline with pravastatin $\left(2.5 \mathrm{~mL} / \mathrm{min} / 1.73 \mathrm{~m}^{2}\right.$ per year slower than in placebo recipients; $P<0.0001)$ in those with severe CKD at baseline (estimated GFR $<40 \mathrm{~mL} / \mathrm{min} /$ $1.73 \mathrm{~m}^{2}$ ) [28]. The aforementioned meta-analysis by Sandhu et al. included 27 randomised trials (39,704 participants) and concluded that, compared with no treatment, statins slowed the loss of GFR by a mean of $1.22 \mathrm{~mL} / \mathrm{min} /$ year [21].

The Study of Heart and Renal Protection (SHARP), a prospective, randomised, controlled study, assessed outcomes in approximately $6300 \mathrm{CKD}$ patients given combination simvastatin/ezetimibe therapy. Concerning the secondary endpoint of progression to ESRD in SHARP, no difference was seen between groups. In fact, one third of the patients in both arms progressed to dialysis or transplantation [29]. Concerning the evaluation of renal function, two prospective, controlled, randomised studies - the aforementioned PLANET I and PLANET II studies-involved 325 patients with type 1 or 2 diabetes with a mean eGFR of $71.2 \mathrm{~mL} / \mathrm{min} / 1.73 \mathrm{~m}^{2}$, and 237 patients with a mean eGFR of $74.9 \mathrm{~mL} / \mathrm{min} / 1.73 \mathrm{~m}^{2}$ at baseline, respectively. Recent results showed that patients on atorvastatin lost about 1 to $2 \mathrm{~mL} / \mathrm{min}$ per $1.73 \mathrm{~m}^{2}$ over 52 weeks, those on rosuvastatin $10 \mathrm{mg} /$ day lost about $4 \mathrm{~mL} / \mathrm{min}$ per $1.73 \mathrm{~m}^{2}$ and those on rosuvastatin $40 \mathrm{mg} /$ day lost close to $8 \mathrm{~mL} / \mathrm{min}$ per $1.73 \mathrm{~m}^{2}$ [30-32].
In nondiabetic patients (PLANET II), the effects of the treatments on kidney function were slightly less pronounced. There was a significant decline in eGFR with rosuvastatin $40 \mathrm{mg} /$ day but not in the other two treatment groups [3032]. Atorvastatin and rosuvastatin exerted different effects on proteinuria and renal function. The differential effects on proteinuria and eGFR in the treatment groups were not a result of differences in lipid lowering. All the treatments lowered total and LDL cholesterol, and there were no significant differences in the amount of lipid lowering [32]. One big question remaining is whether atorvastatin is actually protecting the kidneys or whether rosuvastatin is damaging them [32].

The available data and the evidence are inconclusive to answer the question if statins slow the kidney disease progression. It is premature to recommend statin therapy for renal protection alone. Additional prospective, randomised trials are also needed to determine whether statins are truly renoprotective. Addressing safety, the use of high doses of statins in CKD patients has largely been demonstrated to be safe and well tolerated $[20,23]$.

\section{Does the Use of Statins Lower Cardiovascular Disease Burden on CKD Patients?}

Statins improve the lipid profile in renal patients and exert several pleiotropic effects without major adverse consequences. However, respecting cardiovascular outcomes is critical to the timing of the initiation of the therapy. In the SHARP trial the use of simvastatin plus ezetimibe versus placebo reduced major atherosclerotic events (coronary death, myocardial infarction, nonhaemorrhagic stroke, or any revascularisation) only in the group of patients not on dialysis (risk reduction of 20.2\%). In dialysis patients the difference did not reach statistical significance [29].

This observation corroborates the result of the Prospective Pravastatin Pooling Project that included three large trials: CARE, WOSCOPS, and LIPID studies [33]. Pravastatin also reduced significantly the incidence of myocardial infarction, coronary death, and coronary revascularisation by $23 \%$, only in patients with moderate renal insufficiency [33]. Recently, we also could find, in an observational study, that statins plus vitamin D reduced cardiovascular mortality in predialysis patients (stages 4 and 5) [34].

4.1. CKD Patients on Hemodialysis. On the other hand, it is known from several randomised controlled trials (SHARP, $4 \mathrm{D}$, and AURORA) $[29,35,36]$ that the use of statins in patients already under renal replacement therapy was not protective in terms of mortality and cardiovascular events.

The apparent lack of benefit of using statins in patients in dialysis can have quite a few explanations: the existence of other pathogenic pathways contributing to cardiovascular disease, the high mortality of dialysis patients due to sudden death and cardiomyopathy, situations not preventable by statins, or just because it is too late to interfere with the natural history of atherosclerosis. Moreover, inflammation can play an important role in the dialysis population. 
In the JUPITER study, the administration of rosuvastatin in patients with mild dyslipidaemia but with high CRP levels reduced the number of cardiovascular events [37].

This finding was not unexpected, since statins have an anti-inflammatory effect. This fact can also explain the negative results in the $4 \mathrm{D}$ and AURORA trials, because in these studies the CRP levels remained high despite the use of atorvastatin or rosuvastatin, respectively [38].

Nevertheless, in a recent post hoc analysis of the 4D trial, it was shown that atorvastatin decreased the risk of fatal and nonfatal cardiac events in dialysis diabetic patients with high levels of LDL cholesterol levels [39].

\section{Conclusion}

Statins may have antiproteinuric effects, although the clinical significance of these benefits remains uncertain. The available data and the evidence are inconclusive to answer the question if these agents slow the kidney disease progression. It is premature to recommend statin therapy for renal protection alone.

Regarding prevention of cardiovascular disease, there is a strong clinical evidence of benefit in using statins in early stages of CKD, but there is no clear advantage to its use in dialysis patients, a particular population with a huge cardiovascular risk. Nevertheless these drugs have several pleiotropic effects, and remembering the musical "The Fiddler on the Roof" and the song "If I Were a Rich Man..." maybe we can also use statins in selected dialysis patients; namely, in those with higher LDL cholesterol levels, their use may be advantageous.

\section{Conflict of Interests}

The authors declare no conflict of interests.

\section{References}

[1] A. S. Go, G. M. Chertow, D. Fan, C. E. McCulloch, and C. Y. Hsu, "Chronic kidney disease and the risks of death, cardiovascular events, and hospitalization," New England Journal of Medicine, vol. 351, no. 13, pp. 1296-1370, 2004.

[2] US Renal Data System, "2010 Annual data report," American Journal of Kidney Diseases, vol. 57, supplement 1, pp. e87-e98, 2011.

[3] E. M. Stuveling, S. J. L. Bakker, H. L. Hillege, P. E. de Jong, R. O. B. Gans, and D. de Zeeuw, "Biochemical risk markers: a novel area for better prediction of renal risk?" Nephrology Dialysis Transplantation, vol. 20, no. 3, pp. 497-508, 2005.

[4] W. P. Castelli, K. Anderson, P. W. F. Wilson, and D. Levy, "Lipids and risk of coronary heart disease. The Framingham Study," Annals of Epidemiology, vol. 2, no. 1-2, pp. 23-28, 1992.

[5] M. Manttari, E. Tiula, T. Alikoski, and V. Manninen, "Effects of hypertension and dyslipidemia on the decline in renal function," Hypertension, vol. 26, no. 4, pp. 670-675, 1995.

[6] P. Muntner, J. Coresh, J. C. Smith, J. Eckfeldt, and M. J. Klag, "Plasma lipids and risk of developing renal dysfunction: the atherosclerosis risk in communities study," Kidney International, vol. 58, no. 1, pp. 293-301, 2000.
[7] R. C. Ozsoy, W. A. van der Steeg, J. J. P. Kastelein, L. Arisz, and M. G. Koopman, "Dyslipidaemia as predictor of progressive renal failure and the impact of treatment with atorvastatin," Nephrology Dialysis Transplantation, vol. 22, no. 6, pp. 15781586, 2007.

[8] V. M. Campese and J. Park, "HMG-CoA reductase inhibitors and the kidney," Kidney International, vol. 71, no. 12, pp. 1215-1222, 2007.

[9] R. Agarwal, "Effects of statins on renal function," Mayo Clinic Proceedings, vol. 82, no. 11, pp. 1381-1390, 2007.

[10] C. K. Abrass, "Cellular lipid metabolism and the role of lipids in progressive renal disease," American Journal of Nephrology, vol. 24, no. 1, pp. 46-53, 2004.

[11] O. Samuelsson, H. Mulec, C. Knight-Gibson et al., "Lipoprotein abnormalities are associated with increased rate of progression of human chronic renal insufficiency," Nephrology Dialysis Transplantation, vol. 12, no. 9, pp. 1908-1915, 1997.

[12] H. Oda and W. F. Keane, "Recent advances in statins and the kidney," Kidney International, vol. 56, supplement 71, pp. S-2S-5, 1999.

[13] E. S. Schaeffner, T. Kurth, G. C. Curhan et al., "Cholesterol and the risk of renal dysfunction in apparently healthy men," Journal of the American Society of Nephrology, vol. 14, no. 8, pp. 2084-2091, 2003.

[14] S. Shurraw and M. Tonelli, "Statins for treatment of dyslipidemia in chronic kidney disease," Peritoneal Dialysis International, vol. 26, no. 5, pp. 523-539, 2006.

[15] R. Ross, "Atherosclerosis: an inflammatory disease," New England Journal of Medicine, vol. 340, no. 2, pp. 115-126, 1999.

[16] J. Mimic-Oka, T. Simic, and M. Pljesa, "Oxidative modifications of plasma proteins in different stages of chronic renal failure," Medicine \& Biology, vol. 8, pp. 1-5, 2001.

[17] P. Stenvinkel and A. Alvestrand, "Inflammation in end-stage renal disease: sources, consequences, and therapy," Seminars in Dialysis, vol. 15, no. 5, pp. 329-337, 2002.

[18] P. Stenvinkel, O. Heimbürger, B. Lindholm, G. A. Kaysen, and J. Bergström, "Are there two types of malnutrition in chronic renal failure? Evidence for relationships between malnutrition, inflammation and atherosclerosis (MIA syndrome)," Nephrology Dialysis Transplantation, vol. 15, no. 7, pp. 953-960, 2000.

[19] S. Vázquez-Pérez, P. Aragoncillo, N. De Las Heras et al., "Atorvastatin prevents glomerulosclerosis and renal endothelial dysfunction in hypercholesterolaemic rabbits," Nephrology Dialysis Transplantation, vol. 16, supplement 1, pp. 40-44, 2001.

[20] R. G. Kalaitzidis and M. S. Elisaf, "The role of statins in chronic kidney disease," American Journal of Nephrology, vol. 34, no. 3, pp. 195-202, 2011.

[21] S. Sandhu, N. Wiebe, L. F. Fried, and M. Tonelli, "Statins for improving renal outcomes: a meta-Analysis," Journal of the American Society of Nephrology, vol. 17, no. 7, pp. 2006-2016, 2006.

[22] K. Douglas, P. G. O’Malley, and J. L. Jackson, "Meta-analysis: the effect of statins on albuminuria," Annals of Internal Medicine, vol. 145, no. 2, pp. 117-124, 2006.

[23] G. F. M. Strippoli, S. D. Navaneethan, D. W. Johnson et al., "Effects of statins in patients with chronic kidney disease: meta-analysis and meta-regression of randomised controlled trials," British Medical Journal, vol. 336, no. 7645, pp. 645-651, 2008.

[24] D. G. Vidt, M. D. Cressman, S. Harris, J. S. Pears, and H. G. Hutchinson, "Rosuvastatin-induced arrest in progression of renal disease," Cardiology, vol. 102, no. 1, pp. 52-60, 2004. 
[25] J. M. McKenney, M. H. Davidson, T. A. Jacobson, and J. R. Guyton, "Final conclusions and recommendations of the national lipid association statin safety assessment task force," American Journal of Cardiology, vol. 97, supplement 8, pp. S89-S94, 2006.

[26] V. G. Athyros, D. P. Mikhailidis, A. A. Papageorgiou et al., "The effect of statins versus untreated dyslipidaemia on renal function in patients with coronary heart disease. A subgroup analysis of the Greek atorvastatin and coronary heart disease evaluation (GREACE) study," Journal of Clinical Pathology, vol. 57, no. 7, pp. 728-734, 2004.

[27] M. J. Koren and M. H. Davidson, "ALLIANCE Investigators. Impact of aggressive treatment with atorvastatin in renal function in managed care patients with coronary heart disease: the ALLIANCE study [abstract 1070-123]," Journal of the American College of Cardiology, vol. 45, supplement A, p. 391A, 2005.

[28] M. Tonelli, L. Moyé, F. M. Sacks, T. Cole, and G. C. Curhan, "Effect of pravastatin on loss of renal function in people with moderate chronic renal insufficiency and cardiovascular disease," Journal of the American Society of Nephrology, vol. 14, no. 6, pp. 1605-1613, 2003.

[29] C. Baigent, M. J. Landray, C. Reith et al., "The effects of lowering LDL cholesterol with simvastatin plus ezetimibe in patients with chronic kidney disease (Study of Heart and Renal Protection): a randomised placebo-controlled trial," The Lancet, vol. 377, no. 9784, pp. 2181-2192, 2011.

[30] "Prospective evaluation of proteinuria and renal function in diabetic patients with progressive renal disease," in Proceedings of the 47th European Renal Association-European Dialysis and Transplant Association (ERA-EDTA) Congress, Munich, Germany, June 2010.

[31] A. Olyaei, E. Greer, R. Delos Santos, and J. Rueda, “The efficacy and safety of the 3-hydroxy-3-methylglutaryl-CoA reductase inhibitors in chronic kidney disease, dialysis, and transplant patients," Clinical Journal of the American Society of Nephrology, vol. 6, no. 3, pp. 664-678, 2011.

[32] D. M. Keller, "PLANET I and II: atorvastatin beats rosuvastatin for protecting kidneys in diabetic and nondiabetic patients," http://www.theheart.org/article/1095269.do, 2012.

[33] M. Tonelli, C. Isles, G. C. Curhan et al., "Effect of pravastatin on cardiovascular events in people with chronic kidney disease," Circulation, vol. 110, no. 12, pp. 1557-1563, 2004.

[34] P. L. Neves, A. Malho, A. Cabrita et al., "Statins and vitamin D: a friendly association in pre-dialysis patients," International Urology and Nephrology, vol. 42, no. 1, pp. 173-179, 2010.

[35] C. Wanner, V. Kane, W. Marz et al., "for German diabetes and dialysis study investigators. Atorvastatin in patients with type 2 diabetes mellitus undergoing hemodialysis," The New England Journal of Medicine, vol. 353, pp. 238-248, 2005.

[36] B. C. Fellström, A. G. Jardine, R. E. Schmieder et al., "for the AURORA Study Group. Rosuvastatin and cardiovascular events in patients undergoing hemodialysis," The New England Journal of Medicine, vol. 360, pp. 1395-1407, 2009.

[37] P. M. Ridker, E. Danielson, F. A. H. Fonseca et al., "Rosuvastatin to prevent vascular events in men and women with elevated C-reactive protein," New England Journal of Medicine, vol. 359, no. 21, pp. 2195-2207, 2008.

[38] D. Goldsmith and A. C. Covic, "Editorial: Jupiter or Aurora? Micro-inflammation and dyslipidaemia: twin targets for statin therapy in CKD," International Urology and Nephrology, vol. 42, no. 1, pp. 133-136, 2010.
[39] W. März, B. Genser, C. Drechsler et al., "Atorvastatin and low-density lipoprotein cholesterol in type 2 diabetes mellitus patients on hemodialysis," Clinical Journal of the American Society of Nephrology, vol. 6, no. 6, pp. 1316-1325, 2011. 


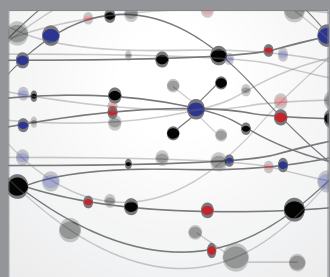

The Scientific World Journal
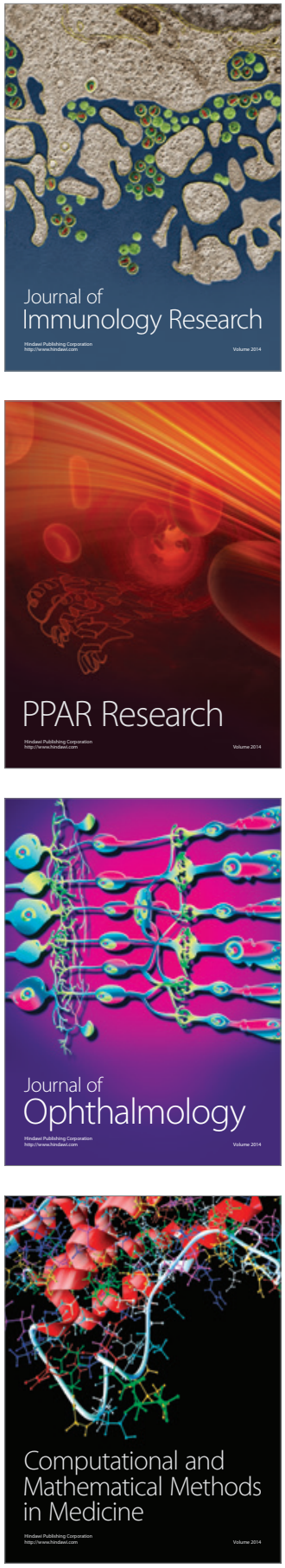

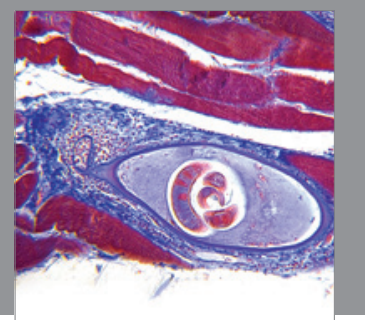

Gastroenterology

Research and Practice
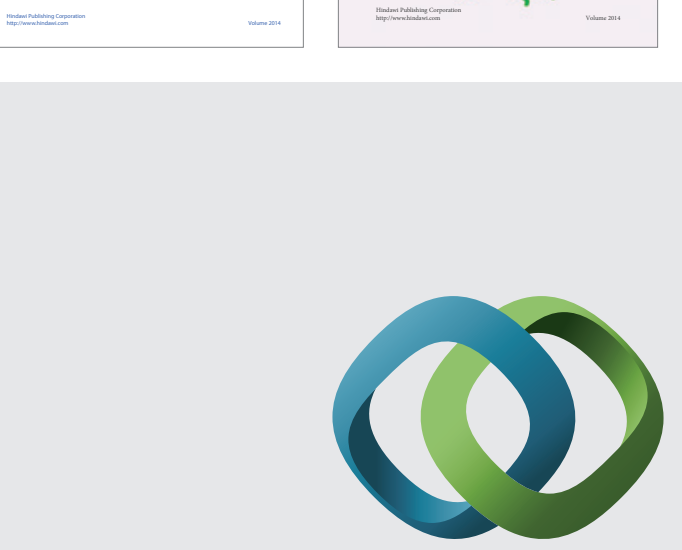

\section{Hindawi}

Submit your manuscripts at

http://www.hindawi.com
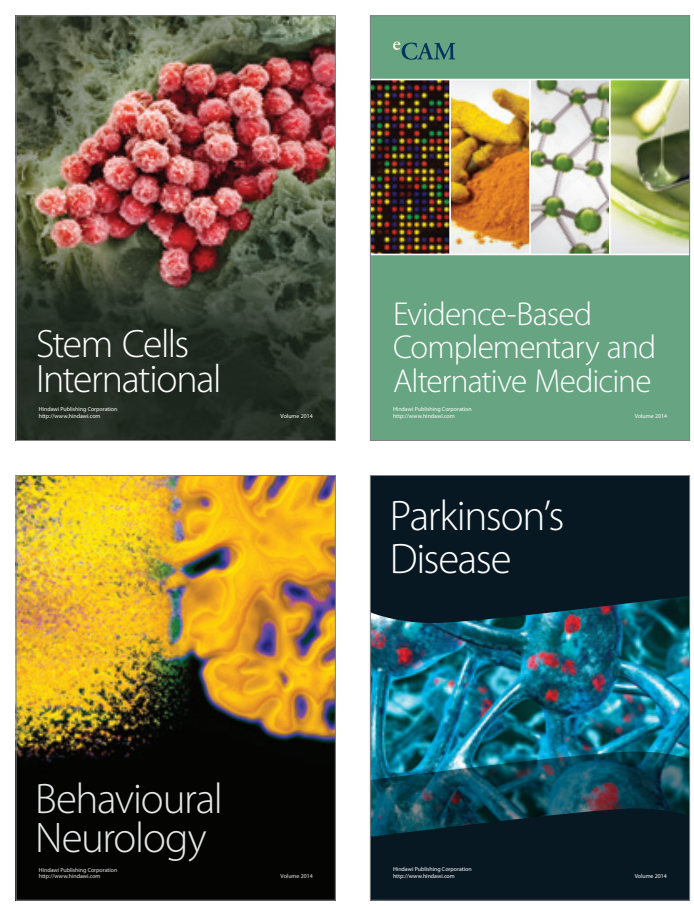

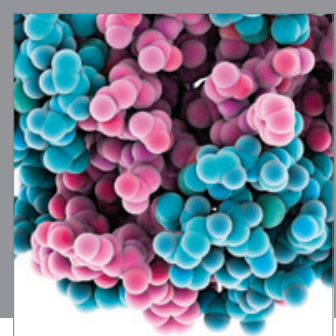

Journal of
Diabetes Research

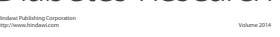

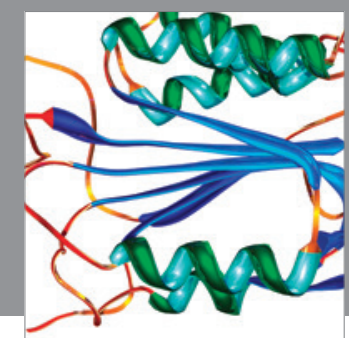

Disease Markers
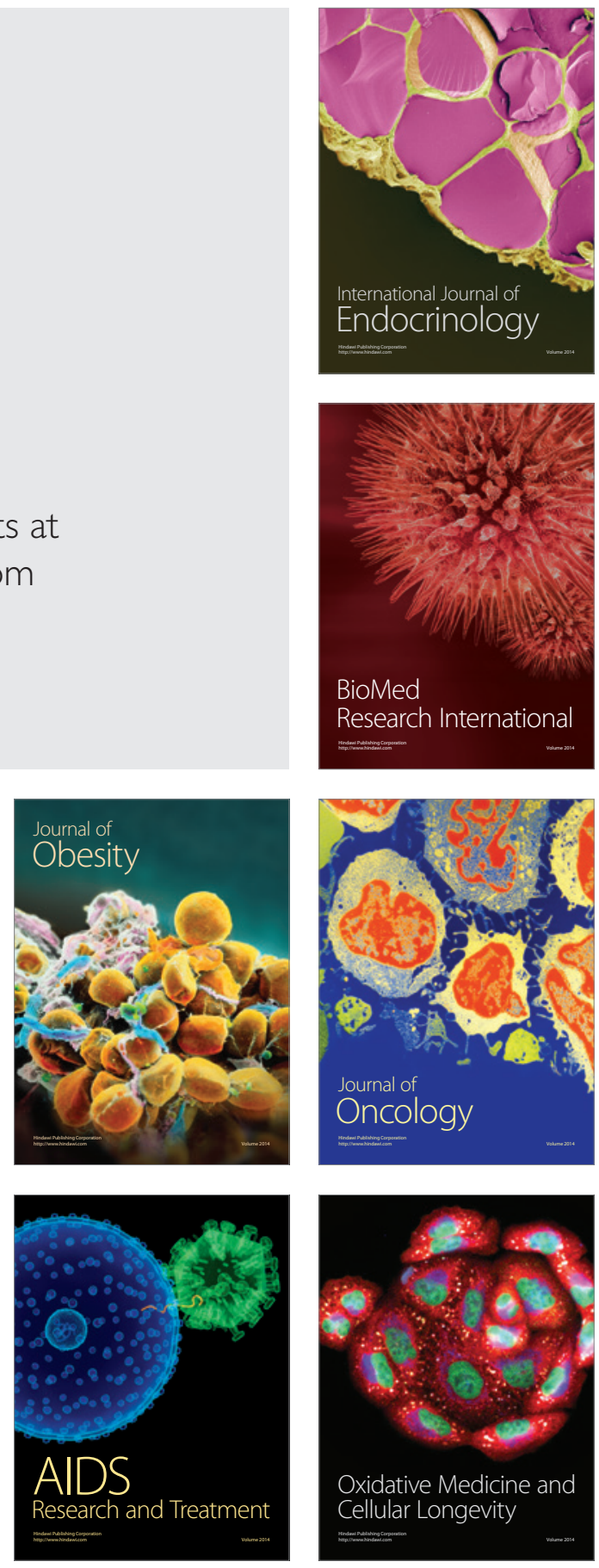